\section{Evaluation of communication behavior in persons with dementia during caregivers' singing}

\author{
Gabriella Engström, ${ }^{1}$ Lena Marmstål,, \\ Christine Williams, ${ }^{3}$ Eva Götell, \\ 'School of Health, Care and Social \\ Welfare, Mälardalen University, \\ Eskilstuna; '2Department of Neurobiology, \\ Care Science, and Society, Karolinska \\ Institute, Sweden; ${ }^{3}$ Christine E. Lynn \\ College of Nursing, Florida Atlantic \\ University, Boca Raton, FI, USA
}

\section{Abstract}

The number of persons with dementia (PWD) is increasing rapidly worldwide. Cognitive impairments and communication difficulties are common among PWD. Therefore, gaining mutual togetherness in caring relation between PWD and their caregivers is important. This study was to investigate the effects of music therapeutic care (MTC) during morning care situations on improving verbal and nonverbal communication behaviors in people with dementia. An observation study with 10 PWD participating. Videotaped interactions (VIO) between PWD and their caregivers were conducted during eight weekly sessions, four recordings consisted of usual morning care and four recordings were of morning care with MTC intervention. The Verbal and Nonverbal Interaction Scale was used to analyze the recorded interactions at a later time. The unsociable verbal variable Cursing decreased significantly $(\mathrm{P}=.037)$ during MTC when compared with the baseline measurement. A significant $(\mathrm{P}=.000)$ reduction was observed for the unsociable nonverbal variable Does not respond to question. MTC significantly $(\mathrm{P}=.01)$ increased the mean score for the sociable nonverbal variable - Calm relaxed. For sociable verbal communication, significant differences were observed for the variables Use coherent communication $(\mathrm{P}=.012)$, Use relevant communication $(\mathrm{P}=.009)$, Responds to questions $(\mathrm{P}=.000)$, Humming $(\mathrm{P}=.004)$, Singing $(\mathrm{P}=.000)$. MTC during morning care situations can be an effective non-pharmacological treatment, as well as nursing intervention in order to improve sociable communication behaviors, as well as reduce unsociable communication behaviors of PWDs.

\section{Introduction}

Alzheimer's disease and other types of dementia are reaching epidemic proportions globally as it is estimated that in about 30 years, approximately 81 million people will be stricken by dementia care, mutuality between persons with dementia (PWDs) and caregivers is one of the most problematic aspects of delivering. ${ }^{1-2}$ Since PWDs suffer from major cognitive impairments, communication with caregivers has often been problematic. Studies of communication in dementia care generally frame the issue in terms of verbal communication, and have delivered conflicting results. ${ }^{3-4}$ For example, Potkins et al. ${ }^{3}$ suggested that caregivers should speak slowly and in short sentences, ask closed-ended questions, and talk about concrete matters. Small et al. ${ }^{4}$ in contrast, argues that slower speech is ineffective as persons with dementia forget the earlier part of the utterance, and that too much verbal communication and too many demands made by caregivers might be challenging for the persons with dementia, and thereby lead to problematic behaviors. Ineffective communication between the caregivers and the PWD often leads to misunderstandings and problematic behavior on the part of the PWD3. Caregivers need communication strategies to deal with language deficits that are simple, readily available and cost effective. Studies of communication in dementia care generally frame the issue in terms of verbal communication only. ${ }^{3-4}$ What is lacking is a study designed to specifically examine both verbal and nonverbal communication between PWDs and their caregivers

In general, non-pharmacological approaches are preferred in the treatment of agitation in PWDs because of serious side effects and increased mortality risk associated with psychoactive drugs. ${ }^{5}$ Several non-pharmacological approaches have been reported and reviews of non-pharmacological interventions, including Reminiscence Therapy, ${ }^{6-7} \quad$ Cognitive Rehabilitation Therapy, ${ }^{8}$ Validation Therapy, ${ }^{9}$ Reality Orientation ${ }^{6}$ Behavioral Therapy, Touch and Massage, and Light Therapy ${ }^{7}$ have found that most of the qualitative and quantitative studies on these interventions and their effects vary in quality. None of these studies have been replicated; it is difficult to draw any general conclusions about their effectiveness. Though, these non-pharmacological treatments have been suggested and are employed by family and professional care-givers. ${ }^{10-14}$

Morning care is a common nursing situation in which PWDs experience frustration with their caregivers as a result of poor communication. The morning care situations are often lead by the caregivers with verbal instructions, including questions, information
Correspondence: Gabriella Engström, Mälardalen University School of Health, Care and Social Welfare, Box 325, SE-63105 Eskilstuna, Sweden. Tel: +46.6153442 - Fax: +46.016153740 .

E-mail: gabriella.engstrom@mdh.se

Key words: music therapeutic care, dementia, intervention, verbal and nonverbal communication.

Funding: this research was supported by funds from Sparbanksstiftelsen Nya, Sweden, Juanniterorden in Sweden and City of Västerås, Demensförbundet, Sweden.

Contributions: GE, LM, EG, CW, study design and manuscript preparation; LM, data collection; GE, data analysis.

Conflict of interest: the authors report no conflicts of interest.

Received for publication: 10 May 2011. Accepted for publication: 31 August 2011.

This work is licensed under a Creative Commons Attribution 3.0 License (by-nc 3.0).

(OCopyright G. Engström et al., 2011

Licensee PAGEPress, Italy

Nursing Reports 2011; 1:e4

doi:10.4081/nursrep.2011.e4

or requests about the dressing procedure. ${ }^{15}$ Recent nursing research contains a range of studies from the use of background music to natural environments focused on improving bathing and morning care situations. ${ }^{16-19}$ Music therapy and singing have been frequently recommended as a means to decrease agitation; ${ }^{20-23}$ however, recent studies present inconsistent results on their effectiveness. For example, Raglio et al. ${ }^{24}$ found that compared to standard care, music therapy sessions reduced behavioral disorder in PWDs, while Cooke et $a .^{25}$ found no significant effect on agitation and anxiety in PWDs following participation in a music program.

Researchers have developed music therapeutic care (MTC) in which caregivers sing for or together with PWDs. ${ }^{26}$ Götell's ${ }^{27}$ study revealed that MTC was preferred during caregiving as it was associated with the greatest mutual affirmative influence on PWDs and caregivers, when compared with standard care and individualized music listening. In an exploratory study on the use of background music and singing during morning care situations, Dennis ${ }^{28}$ interviewed each participating caregiver at the end of each intervention session, and concluded that music and singing could bring about positive changes, especially enhanced wellbeing of PWDs and caregivers. Furthermore, Hammar et al. ${ }^{29}$ interviewed caregivers about their experiences of morning 
care with and without MTC. The researchers concluded that MTC could be a tool for the caregivers to connect with the PWDs in the communication and, thereby, lead to an experience of well being. In a secondary analysis of the interviews concerning morning care situations, Hammar, Götell and Engström ${ }^{29,30}$ concluded that MTC helped the PWDs express abilities and that communication and co-operation with their caregivers was enhanced even if the caregivers' verbal communication was replaced with songs. The ability to communicate both verbally and nonverbally has been investigated by Engström et al. ${ }^{31}$ who studied a resident with severe dementia for 8 weeks during morning care situations with and without MTC. The researchers found that under MTC the resident's sociable verbal and non verbal communication increased by $23 \%$ while the unsociable verbal and nonverbal communication decreased by $80 \%$, when compared to the morning care situations without MTC. However, the study was carried out as a single case study with only one person with dementia. Further research is needed to examine on the impact of MTC on verbal and non-verbal communication among PWDs living in a nursing home, or their family. Therefore, this study was to examine whether MTC during morning care situations could effectively improve verbal and nonverbal communication behaviors in people with dementia or not.

\section{Materials and Methods}

The study results reported here are parts of the intervention study in dementia care on the effectiveness of MTC during morning care situations, comparing morning care situations without MTC (baseline) with morning care situations with MTC (intervention). In the study, the persons with severe dementia served as their own controls, since it is almost impossible to find a control group to match the intervention group. ${ }^{32}$

\section{Sampling}

Following an approval by the Regional Board of Research Ethics, purposive sampling was used to identify potential participants for the study. Participants were recruited from existing residents in two nursing homes for PWDs in an urban area of Sweden. Patients with severe dementia and their professional caregivers were eligible to participate. The head nurse at the nursing home suggested twelve PWDs and their 10 professional female caregivers. The inclusion criteria for the PWD were that they should be native Swedish speakers and, according to the head nurse's perception, had an extensive history of interaction with the caregivers working at the wards, including during morning care situations. Initially, an invitation was sent to the caregivers, which included the purpose and procedure of the study. The caregivers who were interested in study participation were invited to attend a briefing session of the study. During the briefing, the details of the study were presented and a written information sheet was provided for every potential participant. Since all PWDs had suffered from severe dementia, they were unable to understand the information of the study and thus proxy consent was obtained from their next of kin. The next of kin were informed that participation in the study was voluntary and they could withdraw at any time without experiencing penalties or deprivation of care or services for their relatives.

All 12 PWDs' next of kin and all 10 caregivers agreed to participate in the study. Before the data collection started, two of the patients died, leaving behind 10 participants. Therefore, four men and six women remained in the final data analysis. Five of the PWDs were diagnosed with vascular dementia and another five with Alzheimer's disease. Among the 10 caregivers, three caregivers declined their participation prior to starting data collection due to health problems $(n=2)$ or without any explanation $(n=1)$. One caregiver terminated her participation because her PWD relative passed away.

Prior to data collection, PWDs' levels of cognitive impairment were assessed using the Mini Mental Examination (MMSE). ${ }^{33}$ The MMSE scores ranged from $0-12 \quad(\mathrm{M}=3.3$, $\mathrm{SD}=4.02)$. The age of the participants ranged from 66 to 92 years of age $(\mathrm{M}=81.3, \mathrm{SD}=8.23)$ and their period of residence at the nursing home ranged from 1 month to 5.5 years with an average duration of residence of 24.5 months.

\section{Data collection procedure}

The data were gathered during the "morning care situation' when the caregivers cared for the participating PWDs. The morning care situations contained morning routines such as leading the PWD to the bathroom where the PWD sat down and had nightclothes removed, then bathing took place whereby the upper body of the PWD was washed. Following this, the upper body was dressed. Thereafter, bathing of the abdomen took place and underpants were put on, but these were not video recorded. Socks and shoes were put on followed by a walk or wheel chair ride to the sink where teeth were brushed and hair combed. In total, eight video observations consisting of four recordings of usual morning care (baseline) and four recordings of morning care with MTC (intervention) were carried out for all of the 10 participants.

Before the MTC, all participating caregivers were offered a Music Therapeutic Caregiving course at Mälardalen University or a training course on the instructions about how to use MTC by a certified MTC instructor. Six out of 10 caregivers participated either in the university course or the training for instructions. Both courses included practices in songs that the elderly generally would recognize from their past, such as children's songs, sing-along songs and popular songs from the early part of the twentieth century. The caregivers were instructed to choose songs they preferred to sing and continuously sing in front of the PWD relative when providing morning care.

\section{Instrument and data analysis}

The Verbal and Nonverbal Interaction Scale (VNVIS) developed by Williams (unpublished data) was used to analyze 40 baseline and 40 intervention sessions of morning care situations. The VNVIS was developed to rate frequency and occurrence of specific sociable and unsociable communication behaviors of dementia caregivers and care recipients over a period of 10 minutes. The original VNVIS includes 12 sociable and 12 unsociable items. The instrument was modified by the author (Williams, unpublished data) to include items for singing and humming or whistling. The VNVIS contains two scales: one for caregiver's communication behaviors and another one for care recipient's communication behaviors. In this study, only the care recipient version was used. According to the instructions for the VNVIS, the video tapes were scored by rating the occurrence of each communication behavior during each minute of a session. Each minute was treated as a discrete interval for recording the occurrence (score $=1$ ) or nonoccurrence (score $=0$ ) of the target behavior. Communication behaviors were grouped into four categories (subscales): nonverbal, verbal, sociable and unsociable. The subscale scores were obtained by summing scores for behaviors in those categories: sociable verbal, sociable nonverbal, unsociable verbal and unsociable nonverbal. Individual item scores in each of the categories were examined before and during MTC. Prior to the analysis, the first and second authors (GE and LM) were trained on the use of this instrument by the author of the instrument, Christine Williams (unpublished data). Code definitions were reviewed and procedures for scoring were discussed. Practice was obtained by scoring videotapes of a few residents who did not participate in this study. The raters reviewed their results with the author of the instrument (CW) and discussed their coding until consensus was reached. As the VNVIS required 10 minutes of observation, the first 10 minutes of each morning care situation were used for analysis, although some of the recorded morning care situations lasted longer. On the tenth day after all 80 video recorded sessions were analyzed, a test-retest of reliability was performed by two researchers 
watching all 80 videotapes once again with an interclass correlation coefficient of 0.95 , indicating a satisfactory level of reliability.

\section{Statistical analysis}

A student t-test was used to compare the mean scores of the scores between baseline and during intervention. Statistical analyses were performed with the SPSS for Windows, Version 17.0. A P-value of $<0.05$ was considered significant.

\section{Results}

Since two of the baseline observations and three of the MTC intervention observations were less than 10 minutes in duration, they were dropped from the analysis yielding 75 video tapes. Total scores of the observed behaviors at baseline and during MTC are shown in Table 1. A number of the behaviors improved in the expected direction. For sociable verbal communication, significant improvement was observed in five of the nine behaviors. The ability to respond to questions increased by $69 \%$ from a mean score of $1.53(\mathrm{SD}=1.84)$ at baseline to a mean score of $4.95(\mathrm{SD}=3.59)$ during MTC. Furthermore, the nonverbal behavior Calm-relaxed increased significantly during MTC. At baseline, the participants were observed to be calm and relaxed for a mean score of 7.95 ( $\mathrm{SD}=3.44$ ) whereas during MTC, the participants' mean score for Calm relaxed increased by $19 \%$ to a mean of 9.42 ( $\mathrm{SD}=1.38)$. The unsociable verbal communication behavior Cursing decreased significantly during MTC, when compared with baseline. Furthermore, a significant reduction was observed for the behavior Does not respond to question. It decreased from a mean score of $2.27(\mathrm{SD}=2.47)$ at baseline to a mean score of $0.24(\mathrm{SD}=.59)$ during MTC.

The distribution of observed sociable verbal and nonverbal communication and unsociable verbal and nonverbal communication behaviors for usual morning care (baseline) and MTC morning care is shown in Table 2. Sociable verbal communication behaviors decreased $35 \%$ from a mean score of 16.3 $(\mathrm{SD}=15.1)$ at baseline to $10.5(\mathrm{SD}=12.1)$ during MTC sessions. Regarding sociable nonverbal communication behaviors, the mean score increased $25 \%$ from a mean score of 20.1 $(\mathrm{SD}=9.3)$ at baseline to $25.2(\mathrm{SD}=10.3)$ during MTC sessions. The sociable verbal and nonverbal mean score was $36.3(\mathrm{SD}=23.1)$ at baseline, when compared with $35.6(\mathrm{SD}=2.5)$ during MTC. Unsociable verbal and nonverbal communication was observed at baseline with a mean score of $7.0(\mathrm{SD}=9.2)$ and 6.9 $(\mathrm{SD}=6.5)$, respectively, whereas during MTC, respective reductions of $27 \%$ and $26 \%$ were observed, with a mean score of 5.1 (SD=8.9 and 5.1) for both types of communication. The overall unsociable communication mean score decreased $27 \%$, from a mean score of 13.9 $(\mathrm{SD}=14.07)$ at baseline to $10.2(\mathrm{SD}=10.3)$ during MTC.

In summary, during the four MTC sessions, the caregivers continuously sang familiar songs when providing morning care for the PWDs. These PWDs were then able to communicate better with their caregivers. Both the mean scores for the ability to use relevant communication as well as the ability to respond to questions significantly increased, when compared with the 'usual' morning care without caregivers singing to or with the PWDs. However, since we used such a small non-probability sample, the generalizability of the findings is limited.

\section{Discussion}

The most striking result that emerged from this MTC study was that the PWDs were able to respond to questions and produce coherent and relevant communication with their caregivers during MTC significantly more often than during usual morning care situations

Table 1. Comparisons of verbal and nonverbal observations at baseline and during music therapeutic care intervention.

\begin{tabular}{|c|c|c|c|}
\hline & $\begin{array}{l}\text { Baseline } \\
\text { Mean (SD) }\end{array}$ & $\begin{array}{l}\text { Intervention } \\
\text { Mean (SD) }\end{array}$ & T-test value, $\mathrm{P}$ \\
\hline $\begin{array}{l}\text { Sociable Verbal } \\
\text { Uses coherent communication } \\
\text { Uses relevant communication } \\
\text { Responds to questions } \\
\text { Humming } \\
\text { Singing } \\
\text { Uses partner's name } \\
\text { Asks appropriate questions } \\
\text { Asks for reassurance } \\
\text { Reports positive affect }\end{array}$ & $\begin{array}{c}3.16(3.7) \\
1.53(3.4) \\
1.53(1.8) \\
0.05(0.3) \\
0 \\
0(0) \\
1.18(1.2) \\
0.71(1.3) \\
0.37(0.8)\end{array}$ & $\begin{array}{l}1.37(2.0) \\
1.94(3.8) \\
4.95(3.6) \\
0.71(1.3) \\
2.95(4.1) \\
0.16(.83) \\
2.14(2.3) \\
1.54(2.8) \\
0.95(1.7)\end{array}$ & $\begin{array}{l}-2.295,0.012 \\
2.726,0.009 \\
-5.17,0.0005 \\
3.032,0.004 \\
4.43,0.0005 \\
\text { NS } \\
\text { NS } \\
\text { NS } \\
\text { NS }\end{array}$ \\
\hline $\begin{array}{l}\text { Sociable Nonverbal } \\
\text { Calm relaxed } \\
\text { Looks at partner } \\
\text { Appears interested } \\
\text { Affectionate } \\
\text { Positive affect }\end{array}$ & $\begin{array}{l}7.95(3.44) \\
7.34(2.97) \\
5.29(4.1) \\
0.18(0.69) \\
2.97(4.2)\end{array}$ & $\begin{array}{l}9.42(1.4) \\
6.22(3.1) \\
4.03(3.7) \\
0.24(0.89) \\
1.78(3.1)\end{array}$ & $\begin{array}{c}2.424,0.010 \\
\text { NS } \\
\text { NS } \\
\text { NS } \\
\text { NS }\end{array}$ \\
\hline $\begin{array}{l}\text { Unsociable Verbal } \\
\text { Cursing } \\
\text { Doesn't make sense } \\
\text { Shouting } \\
\text { Incoherent } \\
\text { Irrelevant }\end{array}$ & $\begin{array}{l}0.41(0.76) \\
1.45(2.9) \\
0.79(2.0) \\
1.24(2.9) \\
1.18(2.9)\end{array}$ & $\begin{array}{l}0.11(0.39) \\
2.43(3.4) \\
0.78(1.5) \\
1.78(3.2) \\
1.76(3.2)\end{array}$ & $\begin{array}{c}-2.14,0.037 \\
\text { NS } \\
\text { NS } \\
\text { NS } \\
\text { NS }\end{array}$ \\
\hline $\begin{array}{l}\text { Unsociable Nonverbal } \\
\text { Does not respond to questions } \\
\text { Appear aloof } \\
\text { Stares into space } \\
\text { Inappropriate smiles or laughter } \\
\text { Argumentative } \\
\text { Rejecting } \\
\text { Verbalizes negative affect } \\
\end{array}$ & $\begin{array}{l}2.27(2.45) \\
\quad 0(0) \\
2.34(4.1) \\
1.47(3.3) \\
0.16(0.82) \\
0.87(1.36) \\
0.32(0.9) \\
\end{array}$ & $\begin{array}{l}0.24(0.59) \\
0(0) \\
1.97(3.8) \\
1.43(3.3) \\
0.22(0.63) \\
0.84(1,23) \\
0.24(0.72) \\
\end{array}$ & $\begin{array}{c}-4.92,0.0005 \\
\text { NS } \\
\text { NS } \\
\text { NS } \\
\text { NS } \\
\text { NS } \\
\text { NS } \\
\end{array}$ \\
\hline
\end{tabular}

Table 2. Verbal and nonverbal interactions at baseline and during music therapeutic care intervention.

\begin{tabular}{lccc} 
& $\begin{array}{c}\text { Baseline }(\mathrm{n}=37) \\
\text { Mean (SD) }\end{array}$ & $\begin{array}{c}\text { Intervention (n=38) } \\
\text { Mean (SD) }\end{array}$ & T-test value, P \\
Sociable - Total & $36.3(23.1)$ & $35.6(2.5)$ & $-0.123,0.90$ \\
Sociable - Verbal & $16.3(15.1)$ & $10.5(12.1)$ & $-1.844,0.69$ \\
\hline Sociable - Nonverbal & $20.1(9.3)$ & $25.2(10.3)$ & $2.265,0.26$ \\
Unsociable - Total & $13.9(14.07)$ & $10.2(10.3)$ & $-2.26,0.22$ \\
\hline Unsociable - Verbal & $7.0(9.2)$ & $5.1(8.9)$ & $-0.891,0.37$ \\
Unsociable - Nonverbal & $6.9(6.5)$ & $5.1(5.1)$ & $-1.363,0.18$ \\
\hline
\end{tabular}


(without MTC). The findings of this study contribute preliminary evidence on how MTC can be used by nurses as an effective non-pharmacological intervention in dementia care. One behavior, Uses coherent communication, which was expected to increase during MTC was found to decrease. This might be because the PWD was engaged in humming or singing during MTC. Non-pharmacological interventions such as MTC in this study should be considered before pharmacological treatments ${ }^{34-37}$ since they can be more cost-effective. However, such treatment approaches are underutilized even though they hold the potential to reduce disruptive behavior without the risks associated with pharmacological treatment such as oversedation. ${ }^{38}$ The findings of this study suggest that sociable communication of the PWDs increased and their unsociable communication decreased during the MTC sessions. To our knowledge, this is the first study to apply the Verbal and Nonverbal Interaction Scale to determine the outcomes of MTC during morning care situations in people with severe dementia.

During the MTC, the PWDs' expressions of sociable verbal increased in five out of the nine items such as humming and singing, when compared with those at baseline measurement. The improvement of ability to sing supports the previous findings ${ }^{39-40}$ that PWDs have the skills to remember song texts and sing songs even when they experience severe impairment of communication. Music and singing ${ }^{29,30,41}$ brings about a positive change and improves the interaction of the PWDs with their caregivers during morning care regardless of the qualifications of the singer. ${ }^{28,42}$

This study indicated that participants were significantly more calm-relaxed during MTC. Studies on music therapy by Berger et al.$^{43}$ and Clair, Mathews and Kosloski ${ }^{44}$ also reported increased positive emotions while PWDs sang and participated in music therapy sessions. Bigand, Filipic and Lalitte ${ }^{45}$ argued that there was no doubt that emotion was at the core of musical experience; and they suggested that basic emotions such as happiness could be recognized in and induced by musical stimuli. One important difference, which sheds light on the importance of music therapy, is that MTC is so unique that it can be implemented in everyday caring situations and requires no special equipment other than the caregiver's singing voice, and minimal training.

Nursing studies on communication enhancement in dementia care reported that too much verbal communication or too many instructions from the caregivers might be challenging for the PWD to handle. ${ }^{46,47}$ In this study, caregivers decreased their instructions and instead continuously sang when providing morning care during MTC sessions; and consequently, the PWDs significantly increased their ability to use relevant communication and ask relevant questions. Based on these findings and other MTC study results, ${ }^{16-30,48,49}$ we suggest that during MTC sessions, verbal communication and instructions that are normally referred to through speech can be excluded and instead use MTC in order to enhance communication in the encounters between the PWDs and their caregivers.

In addition, this study also revealed that the unsociable verbal variable, Cursing, significantly decreased during MTC. While cursing could be seen as a means to express aggressive behaviors, MTC may be able to reduce aggression among PWDs, as suggested by a few studies. ${ }^{16-30,41}$ It is also suggested that PWDs' aggressive behaviors are grounded in the difficulties that they encountered in interpreting and expressing verbal and non-verbal communication. ${ }^{50}$ Given that aggressive behaviors decreased and the PWDs could communicate more appropriately during MTC, singing may be beneficial for decreasing aggressive behavior. In all participants, MTC enhanced social function by providing opportunities for the PWDs to participate and cooperate in their activities of daily living.

\section{Implications}

Since MTC requires no special equipment it can easily be implemented in everyday care situations in which PWDs and their caregivers interact. However, without knowledge of correct singing technique or knowledge of the songs preferred by the PWDs, singing when performing care can be demanding for caregivers. We suggest, as do Chatterton, Baker and Morgan ${ }^{42}$ and Dennis, ${ }^{28}$ that MTC should be implemented as an alternative psychosocial intervention in dementia care. A music therapist, a singing instructor/teacher, or a singing nurse, physician or caregiver can take the responsibility of instructing other personnel in how to use MTC as a tool to enhance communication between caregivers and PWDs. In addition, knowledge and training of MTC should be included in the caregivers' education. It is of great importance that MTC is endorsed at the management level to ensure appropriate organizational structures to support the caregivers in its implementation. MTC can be individualized to accommodate residents' preferences, which may encourage the PWDs to join the singing, humming or whistling, and become an active participant rather than a passive listener. Singing is also widely enjoyed as a means of expression across all cultures and geographical regions, which make MTC becoming a good choice in diverse populations.

\section{Limitations and recommendations}

\section{for research}

Limitations of this study included that our sample only contained caregivers willing to be studied together with the PWDs. Since the caregivers were suggested by the head nurse at the nursing home and all agreed to participate, we do not believe that the sample was biased towards either those who liked singing or those who did not enjoy it. However, it should be kept in mind that those who agreed to participate may have done so because they liked singing.

The PWDs were chosen solely due to the head nurse's preferences and perceptions that those PWDs were well known and supported by their caregivers. Moreover, other people with dementia were not selected due to their MMSE scores and the inclusion criteria. These might have limited the representativeness of the sample to the dementia population. The differences in the caregivers' reactions towards their relatives with dementia or their ways of communication were not fully considered in this study. Some next-of-kin refused the invitation to participate therefore those who agreed may have differed in some way. All correspondence with the next of kin was done by the second author.

In this study, morning care sessions were video recorded. Video recording provided a suitable method to capture episodes of verbal communication and nonverbal communication that are usually difficult to observe in real life. Latvala, Voukila-Oikkonen and Janhonen ${ }^{51}$ have noted the importance of ensuring that video recording be conducted with minimal interference with the normal situation. In this study, an attempt was made not to disturb the morning care and to preserve the integrity of both the PWDs and their caregivers. Polit and Beck ${ }^{32}$ pointed out that the researcher should be aware of the Hawthorne effect in which those who are being video recorded may try to please the researchers by behaving in ways they believe are in line with the researcher's purposes. However, we have no reason to believe the participants in this study were distracted by the videotaping; indeed, all of the PWD participants adapted to the camera and appeared not to notice it. The PWDs were all diagnosed with severe dementia and participated in data collection once a week for a relatively short period of about two months. During this process, we observed no major differences in either the social behaviours of the PWDs or those of their caregivers.

This study included the PWDs living in nursing homes and thus the findings might not be able to generalise to the wider population of PWDs, especially those living in their own homes. Further research is recommended in this promising area and should include morning care situations between family caregivers and their PWD relatives, while they are living 
together and professional caregivers provide home visits for them.

\section{References}

1. Ferri C, Prince M, Brayne C, et al. Global prevalence of dementia: A Delphi consensus study. Lancet 2005;366:2112-7.

2. Hansebo G, Kihlgren M. Carers' interactions with patients suffering from severe dementia: A difficult balance to facilitate mutual togetherness. J Clin Nurs 2002;11:225-36.

3. Potkins D, Myint P, Bannister C, et al. Language impairment in dementia: impact on symptoms and care needs in residential homes. Int J Geriatr Psychiatry 2003;18:1002-6.

4. Small JA, Gutman G, Makela S, Hillhouse B. Effectiveness of communication strategies used by caregivers of persons with Alzheimer's disease during activities of daily living. J Speech Lang Hear Res 2003;46:353-67.

5. Ballard C, Waite J, Birks J. Atypical antipsychotics for aggression and psychosis in Alzheimer's disease. Cochrane Database Syst Rev 2008;(1):CD003476.

6. Spector A, Orrell M, Davies S, Woods B. Reality orientation for dementia. Cochrane Database Syst Rev 2000;(4): CD001119.

7. The Swedish Council on Technology Assessment in Health Care [SBU]. Dementia - Caring Ethic, Ethical and Economical Aspects: A Systematic Review (SBU- report, 172E/3). Stockholm: The Swedish Council on Technology Assessment in Health Care; 2008.

8. Clare L, Woods RT, Moniz Cook ED, et al. Cognitive rehabilitation and cognitive training for early-stage Alzheimer's disease and vascular dementia. Cochrane Database Syst Rev 2003;(4):CD003260.

9. Woods B, Spector A, Jones C, et al. Reminiscence therapy for dementia. Cochrane Database Syst Rev 2005;(2): CD001120.

10. Neal M, Briggs M. Validation therapy for dementia. Cochrane Database Syst Rev 2003;(3):CD001394.

11. Egan M, Bérubé D, Racine G, et al. Methods to enhance verbal communication between Individuals with Alzheimer's disease and their formal and informal caregivers: A systematic review. Intl $\mathrm{J}$ Alzheimers Dis 2010.pii:906818.

12. Hulme C, Wright J, Crocker T, et al. Nonpharmacological approaches for dementia that informal carers might try or access: a systematic review Int J Geriatr Psychiatry 2010;25:756-63.
13. Kverno K, Black B, Nolan M, Rabins P. Research on treating neuropsychiatric symptoms of advanced dementia with nonpharmacological strategies, 1998-2008: a systematic literature review. Int Psychogeriatr 2009;21:825-43.

14. Kolanowski A, Fick D, Frazer C, Penrod J. It's about time: use of nonpharmacological interventions in the nursing home. J Nurs Scholarsh 2010;42:214-22.

15. Hammar L, Emami A, Engström G, Götell E. Communicating through caregiver singing during moring care situations in dementia care. Scand J Caring Sci 2011;25:160-8.

16. Kihlgren M, Kuremyr D, Norberg A, et al. Nurse-patient interaction after training in integrity promoting care at a long-term ward: analysis of video-recorded morning care sessions. Int J Nurs Stud 1993;30:113.

17. Ekman SL, Norberg A, Wahlin TB, Winblad B. Dimensions and progression in the interaction between bilingual/monolingual caregivers and bilingual demented immigrants: analysis of video-recorded morning care sessions in institutions coded by means of the Erikson theory of "eight stages of man". Int J Aging Hum Develop 1995;41:29-45.

18. Clark ME, Lipe AW, Bilbrey M. Use of music to decrease aggressive behaviors in people with dementia. J Gerontol Nurs 1998;24: 10-7.

19. Slone P, Hoeffer B, Mitchell M, et al. Effect of person-centered showering and the towel bath on bathing-associated aggression, agitation and discomfort in nursing home residents with dementia: A randomized, controlled trial. J Am Geriatr Soc 2004;52:1795-804.

20. Gerdner L. An individualized music intervention for agitation. J Am Psychiatr Nurs Assoc 1997;3:177-84.

21. Ragneskog H, Asplund K, Kihlgren M, Norberg A. Individualized music played for agitated patients with dementia: Analysis of video-recorded sessions. Int $\mathrm{J}$ Nurs Pract 2001;7:146-55.

22. Ragioli A, Bellelli G, Traficante D, et al. Efficacy of music therapy in the treatment of behaviour and psychiatric symptoms of dementia. Alzheimer Dis Assoc Disord 2008;22:158-62.

23. Gerdner L, Schoenfelder D. Evidence based guideline. Individualized music for elders with dementia. J Gerontol Nurs 2010;36:7-15.

24. Raglio A, Bellelli G, Traficante D, et al. Efficacy of music therapy treatment based on cycles of sessions: a randomised controlled trial. Aging Ment Health 2010;14:900-4.

25. Cooke ML, Moyle W, Shum DH, et al. A randomized controlled trial exploring the effect of music on agitated behaviors and anxiety in older people with dementia. Aging Ment Health 2010;14:905-16.

26. Brown S, Götell E, Ekman SL. "Music Therapeutic Caregiving": the necessity of active music-making in clinical care. Arts Psychother 2001;28:125-35.

27. Götell, E. Singing, background music and music events in the communication between persons with dementia and their caregivers. Thesis. Neurotec Department, Center of Excellence in Elderly Care Research, Karlskrona, Sweden, 2003.

28. Dennis E. It's a good thing to have, to keep you happy. J Dementia Care 2011;19:37-8.

29. Hammar L, Götell E, Engström G. Singing while caring for persons with dementia: single case analysis of video-recorded sessions. Arts \& Health 2011;3:39-50.

30. Hammar L, Emami A, Engström G, Götell E. The impact of caregiver singing on expressions of emotion and resistance during morning care situations in persons with dementia: an intervention in dementia care. J Clin Nurs 2011;20:969-78.

31. Engström G, Marmstål L, Williams C, Götell E. The impact of singing in caring for persons with dementia. Single case analysis of video recorded sessions. Music Med 2011;3:95-101.

32. Polit DF, Beck CT. Nursing research: generating and assessing evidence for nursing practice. Eighth Edition. Philadelphia: Lippincott Williams \& Wilkins; 2008.

33. Folstein MF, Folstein SE, McHugh PR. 'Mini-mental state'. A practical method for grading the cognitive state of patients for the clinician. J Psychiatr Res 1975;12:18998.

34. Cohen-Mansfield J, Thein K, Dakheel-Ali $\mathrm{M}$, et al. The value of social attributes of stimuli for promoting engagement in persons with dementia. J Nerv Ment Dis 2010; 198:586-92.

35. Herrmann N, Gauthier S. Diagnosis and treatment of dementia: 6 . Management of severe Alzheimer disease. CMAJ 2008;179: 1279-87.

36. Ballard C, Corbett A, Chitramohan R, Aarsland D. Management of agitation and aggression associated with Alzheimer's disease: controversies and possible solutions. Curr Opin Psychiatry 2009;22:53240.

37. Vasse E, Vernooij-Dassen M, Spijker A, et al. A systematic review of communication strategies for people with dementia in residential and nursing homes. Int Psychogeriatr 2010;22:189-200.

38. Dettmore D, Kolanowski A, Boustani M. Aggression in persons with dementia: use of nursing theory to guide clinical practice. Geriatr Nurs 2009;30:8-17.

39. Cuddy LL, Duffin J. Music, memory and 
Alzheimer's disease: Is music recognition spared in dementia, and how can it be assessed? Med Hypotheses 2005;64:22935 .

40. Ridder HM, Aldridge D. Individual music therapy with persons with frontotemporal dementia: singing dialogue. Nordic J Music Ther 2005;14:91-106.

41. Götell E, Brown S, Ekman SL. Caregiver singing and background music in dementia care. West J Nurs Res 2002;24:195-216.

42. Chatterton W, Baker F, Morgan K. The singer or the singing: who sings individually to persons with dementia and what are the effects? Am J Alzheimers Dis Other Demen 2010;25:641-9.

43. Berger G, Bernhardt T, Schramm U, et al. No effects of a combination of caregivers support group and memory training/music therapy in dementia patients from a mem- ory clinic population. Int $\mathrm{J}$ Geriatr Psychiatry 2004;19:223-31.

44. Clair AA, Mathews RM, Kosloski K. Assessment of active music participation as an indication of subsequent music making engagement for persons with midstage dementia. Am J Alzheimers Dis Other Demen 2005;20:37-40.

45. Bigand E, Filipic S, Lalitte P. The time course of emotional responses to music. Ann N Y Acad Sci 2005;1060:429-37.

46. Normann HK, Asplund K, Karlsson S, et al. People with severe dementia exhibit episodes of lucidity. A population-based study. J Clin Nurs 2006;15:1413-7.

47. Normann HK, Asplund K, Norberg A. Episodes of lucidity in people with severe dementia as narrated by formal carers. J Adv Nurs 1998;28:1295-300.

48. Götell E, Brown S, Ekman SL. Influence of caregiver singing and background music on posture, movement, and sensory awareness in dementia care. Int Psychogeriatr 2003;15:411-30.

49. Götell E, Brown S, Ekman SL. The influence of caregiver singing and background music on vocally expressed emotions and moods in dementia care: a qualitative analysis. Int J Nurs Stud 2009;46:422-30.

50. Almvik R, Rasmussen K, Woods $\mathrm{P}$. Challenging behaviour in the elderly-monitoring violent incidents. Int $\mathrm{J}$ Geriatr Psychiatry 2006;21:368-74.

51. Latvala E, Voukila-Oikkonen P, Janhonen S. Videotaped recording as a method of participant observation in psychiatric nursing research. J Adv Nurs 2000;31: 1252-7. 